\title{
A cross-sectional study of risk factors and hypertension among adolescent Senior High School students
}

This article was published in the following Dove Press journal: Diabetes, Metabolic Syndrome and Obesity: Targets and Therapy

\section{Cecilia Amponsem-Boateng Weidong Zhang Timothy Bonney Oppong Godfrey Opolot Emmanuel Kumi Duodu Kyere}

Department of Epidemiology and Biostatistics, College of Public Health, Zhengzhou University, Zhengzhou, 45000I, People's Republic of China
Correspondence: Weidong Zhang Department of Epidemiology, School of Public Health, Zhengzhou University, Henan 45000I, People's Republic of China $\mathrm{Tel}+86037167781964$

Email imooni@I63.com

\begin{abstract}
Introduction: Hypertension is among the first five causes of mortality, globally contributing more than $40 \%$ to cardiac related deaths worldwide, with almost $70 \%$ cardiovascular deaths in the low- and middle-income countries. Its burden is projected to be 150 million by 2025 based on epidemiological data within the Sub-Saharan Africa regions, with Ghana experiencing 505,180 increases in 2007. It is currently among the leading cause of death in the country, with prevalence ranging from $19 \%$ to $48 \%$. There is limited data concerning hypertension on Ghanaian youth. Particularly, on those at the Senior High School (SHS) level that represents the immediate workforce of the country on the depth of prevalence, knowledge as well as the risk factors that may predispose them into having prehypertension and hypertension for proper records and interventional measures and that is what this study pursues to do.
\end{abstract}

Materials and methods: A cross-sectional study was employed in five different SHSs in the Ashanti region of Ghana from December 2018 to February 2019 with structured questionnaires and physical screening of participants. Logistic regression analysis was performed to test for relation knowledge and riskfactors on HTN.

Results: The overall prevalence of pre-HTN within the group was $33.8 \%$, with stages 1 and 2 HTN prevalence of 5.4\%. Sixty-three percent do not have an idea of what HTN is, and positive associations were found between no physical exercises, no addition of extra salt, type of food often eaten and family history.

Conclusion: This study establishes prevalence in pre-HTN within students at the SHS level with low knowledge and high risk factors on the disease. This indication is beneficial to target the interventional programs on this population at this early stage by inculcating education on HTN prevalence and its risks in the educational curricular by the government. Keywords: hypertension, hip circumference, BMI, youth, age, metabolic syndrome

\section{Introduction}

Hypertension(HTN) still remains one of the five leading cause of mortality globally, with more than $40 \%$ of deaths related to cardiac diseases. ${ }^{1}$ This accounts for 9.4 million deaths and a minimum of $45-51 \%$ cardiovascular diseases (CVDs). With nearly $70 \%$ deaths related to CVDs in the low- and middle-income countries (LMICs), the WHO data predict a 1.56 billion (60\%) increase in the global burden by the year $2025,{ }^{2}$ while almost 3 of every 4 hypertensive patients would be living in the LMICs. ${ }^{3}$ Hypertension prevalence has increased from almost 80 million adults in Sub-Saharan Africa from the year 2000 to an estimated increase of 150 million in 2025 based on current epidemiological data. ${ }^{3}$ Again in Sub-Saharan Africa, a study of four regions reveals a burden of $25.9 \%$ with associated risks 
factors such as older age, body mass index (BMI), level of education among others. ${ }^{4}$

Over the past few years, Ghana has witnessed more than a ten-fold increase from 49,087 in 1988 to 505,180 in 2007 , with an increase in outpatient disease from $1.7 \%$ to $4.0 \%$ in all ages. ${ }^{5}$ As an important cause of heart and renal failure in Ghana, HTN and stroke have been among the leading cause of admission and death in the country. ${ }^{6}$ Prevalence of HTN in Ghana ranges between $19 \%$ and $48 \%$ within rural and urban communities, and studies have shown a fraction of $21.4 \%$ and higher in men of all age groups in this country, ${ }^{7}$ though another study discloses a $13 \%$ prevalence of HTN among people within the ages of 15-49 in Ghana with low awareness. ${ }^{8}$ The above-mentioned statistics all relate to adult populations. However, the prevalence of hypertension is estimated to be $1-2 \%$ and is reported to be on the increasing trend among adolescents largely due to the current obesity epidemic in children. ${ }^{9}$

Knowledge gaps are key obstructions in the effective avoidance and treatment of HTN. ${ }^{10}$ Knowledge in the form of health literacy allows individuals to progress on their health outcomes. Although this does not rest solely on the capability of skills of the individual, ${ }^{11}$ research has shown a positive relationship on the proportion of knowledge, with persons with blood pressure under control. ${ }^{12}$ It has been reported that knowledge and understanding of possible risks related to HTN and probable effects of lifestyle changes are insufficient in Ghana as the country still experiences misconceptions and gaps on knowledge on HTN in its rural communities. Official education, communication gaps and unreachability to routine health instruction programs among others have been well-known to impede on the knowledge on HTN. ${ }^{7}$ The Fourth Report on the Diagnosis, Evaluation, and Treatment of High Blood Pressure in Children and Adolescents, published as far back in 2004, also established the condition "prehypertension" in parallel with adult hypertension guidelines. The long-term health risks for hypertension in children and adolescents can be extensive. ${ }^{13}$ It is actually estimated that the presence of high blood pressure in children with normal weight is highly overlooked. ${ }^{14}$ A proper record of the depth of knowledge and its risks of HTN among a population, which represents the immediate workforce of the country, is necessary to effectively monitor and draw health campaign programs as far as HTN is concerned. This study, therefore, conveys evidence on the prevalence, knowledge as well as risk factors of HTN in students in Ghana at the Senior High
School (SHS) Level who are the representation of the immediate workforce of the country.

\section{Materials and methods}

\section{Study settings and participants}

This cross-sectional study engaged a convenience sampling at five SHSs in the Ashanti Region of Ghana from November 2018 to February 2019. Due to the current rotational shift method employed by the Ghana education Services on its curricular, students who were immediately available at the scheduled time of any particular school and gave approval were recruited to partake in this study. Public SHSs which were directly under the education directorate were targeted. The Ashanti Region was chosen because of its location in the middle belt of the country and the fact that permission had been granted by the Service Directorate (Reference No. 14/90/33) to conduct the study.

\section{Procedure for collection of data and data collection tool}

Measurement of blood pressures of participants was taken in accordance with the "Pan-African Society of Cardiology" (PASCAR) recommendations in 2014, ${ }^{15}$ by using automatic (MOTECH TrueScan, Germany blood pressure monitors) and a mercury sphygmomanometer. Due to resource and logistical constraints, multiple measurements for all participants were not done. However, participants with high readings were asked to sit for 30 mins after which readings were repeated and an average reading was recorded to the nearest $\mathrm{mmHg}$.

The (Detecto Stainless steel 437) was used to measure weights of participants while heights were measured by the height rod and stadiometers. BMI was calculated by dividing the weight $(\mathrm{kg})$ by the height $\left(\mathrm{m}^{2}\right)$ and categorized under standard approvals by the WHO. Waist circumference was taken and recorded in centimeters; for females it was grouped as $<70 \mathrm{c} \mathrm{cm}$ as very low, $70-89 \mathrm{~cm}$ as low, 90-109 as high and $\geq 110$ as very high while that for males it was grouped as $<80 \mathrm{~cm}$ as very low, $80-99 \mathrm{~cm}$ as low and $110-120$ as high.

All individual information on a participant was written on their respective coded questionnaire, which they filled after they were through with the screening exercise, and submitted to the group performing the screening. The questionnaire contained three parts, with part one measuring the sociodemographic characteristics of participants. 
Part two focused on knowledge of hypertension among the participants, whereas the last part focused on the possible risk factors of hypertension among the participants. Particularly, risk factors focused on physical activities, salt intake and general diet of participants. Professional nurses and a professional medical doctor were engaged throughout the screening period. Blood pressure readings were classified according to the Seventh Report of the Joint National Committee on Prevention, Detection, Evaluation, and Treatment of High Blood Pressure (JNC 7), 2003. ${ }^{16}$ Categories were normal with systolic blood pressure (SBP) $\geq 120$ and diastolic blood pressure (DSB) 80; pre-HTN as SBP 120-139 and DBP 80-89; stage 1 as SBP 140-159 and DBP 90-99 and stage 2 with SBP $\geq 160$ and DBP $\geq 100$.

\section{Ethical consideration}

This study was approved by Zhengzhou university's ethical committee and permission was granted by the Service Directorate with (Reference no. 14/90/33). Official letters were also dispersed to heads of schools. Heads of schools were asked to introduce the study to parents of students during a Parent Teacher Association (PTA) meeting. Parents who did not want their children to participate in the study were asked to identify themselves and also inform their children not to report at the study grounds. Therefore, researchers assumed that parents had given their consent if students reported at the study grounds. Again, verbal approval was sought from partakers before registering them into the study. For purposes of secrecy, the names of participants or schools are not contained in this study.

\section{Data analysis}

Data were imputed and analyzed by using SPSS version 24 , and multinomial logistic regression was used to test for the strength of associations between variables, while a $P$-value of $\leq 0.05$ was set as significant.

\section{Results}

\section{Background characteristics and anthropometric measurements}

Respondents were all SHS students within the study area. As depicted in Table 1, the mainstream (571) of them were between the ages of 15-17 years representing 49.2\%, while the lesser (128) representing $11 \%$ were less than 15 years. Females formed $61.2 \%$ of the population studied, and 462 signifying almost $40 \%$ of participants had their heights between 151 and $160 \mathrm{~cm}$, while (29) which $2.5 \%$ were less than $140 \mathrm{~cm}$.

Four hundred and seventy representing $40.5 \%$ weighed between 51 and $60 \mathrm{~kg}$ and formed the majority, whereas 20 representing $1.7 \%$ weighed less than $40 \mathrm{~kg}$. Most of the femaleparticipants $(37 \%)$ were within the normal hip circumference range, $4 \%$ had very high and $2.9 \%$ had very low, while their male counterparts had $61.3 \%, 0.9 \%$ and $8.5 \%$ of them with normal, very high and very low hip circumferences ranges, respectively. On BMI classification, $58.9 \%$ were within the normal range, while $0.3 \%$ were class 3 obesity.

\section{Prevalence of hypertension}

Among the 1,161 students who fully participated in this study, 705 representing $60.7 \%$ were within the normal ranges of HTN. The study realized a $33.5 \%, 5.1 \%$ and $0.7 \%$ prevalence of pre-HTN, stage 1 and stage $2 \mathrm{HTN}$ within its participants. The distribution of HTN with age and gender is presented in Figures 1 and 2, respectively. A total of 200 representing $51.4 \%$ with pre-HTN were within the age ranges of $15-17$ years followed by the age group of $\geq 18$ with $n=161(41.4 \%)$ and $n=28$ representing $7.2 \%$ for respondents who were $<15$ years. However, $61 \%$ of respondents with stage 1 HTN were $\geq 18$, followed by ages $15-17$ years with $30.5 \%$. Distribution of hypertension by gender revealed more female $441(62.6 \%)$ with normal reading than males as well as female having a higher proportion $58.6 \%$ with preHTN. Female were also more than males in stages one and two with $64.4 \%$ and $62.5 \%$ correspondingly.

Table 2 shows the knowledge of HTN within respondents. Overall, $63 \%$ of respondents do not have an idea of what HTN is, while $52.3 \%$ do not know whether a family member has the disease or not. A few 3.0\% have been diagnosed with HTN before and $40.9 \%$ do not know the causes of HTN.

Table 3 a, presents the associations between age and gender on knowledge on HTN and $3 \mathrm{~b}$, is on associations between risk factors and knowledge on HTN. The study finds a positive association between the age ranges of 1517 years , as well as $\geq 18$ years with CI of (0.255-0.638) and (0.266-0.675) correspondingly. It also found possitive association with being female and hypertension with CI: (1.056-1.729). Again, there were positive associations on those who do not engage in any physical exercises at all (CI: 1.048-1.932), who said "NO" to add extra salt to cooked foods (CI: 1.106-1.897) and the type of foods 
Table I Background characteristics and anthropometric measurements and its relationship between HTN of respondents

\begin{tabular}{|c|c|c|c|c|c|}
\hline Variables & & Frequency & Percentage & $\begin{array}{l}\text { Pearson(chi squre) } \\
X^{2}\end{array}$ & $P$-value \\
\hline $\begin{array}{l}\text { Age (years) } \\
\quad 15-17 \\
\geq 18 \\
<15\end{array}$ & & $\begin{array}{l}571 \\
462 \\
128\end{array}$ & $\begin{array}{l}49.2 \\
39.8 \\
11.0\end{array}$ & 23.474 & $0.003^{* *}$ \\
\hline $\begin{array}{c}\text { Gender } \\
\text { Female } \\
\text { Male }\end{array}$ & & $\begin{array}{l}710 \\
451\end{array}$ & $\begin{array}{l}61.2 \\
38.8\end{array}$ & 4.463 & 0.347 \\
\hline $\begin{array}{l}\text { Height }(\mathrm{cm}) \\
\qquad|4|-150 \\
15 \mid-160 \\
>160 \\
<140\end{array}$ & & $\begin{array}{l}354 \\
462 \\
316 \\
29\end{array}$ & $\begin{array}{l}30.5 \\
39.8 \\
27.2 \\
2.5\end{array}$ & 44.852 & $0.000 * * *$ \\
\hline $\begin{array}{l}\text { Weight (kg) } \\
41-50 \\
51-60 \\
61-70 \\
<40\end{array}$ & & $\begin{array}{l}266 \\
470 \\
316 \\
20\end{array}$ & $\begin{array}{l}22.9 \\
40.5 \\
27.2 \\
1.7\end{array}$ & 109.510 & $0.000 * * *$ \\
\hline $\begin{array}{l}\text { BMI } \\
\qquad \begin{array}{l}\text { I8.5-24.9 } \\
25.0-29.9 \\
30.0-34.9 \\
35.0-39.9 \\
40 \text { and above }\end{array}\end{array}$ & $\begin{array}{l}\text { normal } \\
\text { overweight } \\
\text { Class I obesity } \\
\text { Class II obesity } \\
\text { Class III obesity }\end{array}$ & $\begin{array}{l}684 \\
314 \\
68 \\
14 \\
3\end{array}$ & $\begin{array}{l}58.9 \\
27.0 \\
5.9 \\
1.2 \\
0.3\end{array}$ & 153.235 & $0.000 * * *$ \\
\hline $\begin{array}{l}\text { Hip circumference wo } \\
\text { Normal } \\
110 \mathrm{~cm} \text { and above } \\
70-89 \mathrm{~cm} \\
90-109 \mathrm{~cm} \\
<70 \mathrm{~cm}\end{array}$ & $\begin{array}{l}\text { nen } \\
\text { very high } \\
\text { low } \\
\text { high } \\
\text { very low }\end{array}$ & $\begin{array}{l}430 \\
46 \\
256 \\
395 \\
34\end{array}$ & $\begin{array}{l}37.0 \\
4.0 \\
22.0 \\
34.0 \\
2.9\end{array}$ & 75.790 & $0.000 * * *$ \\
\hline $\begin{array}{l}\text { Hip circumference m } \\
\text { Normal } \\
110-120 \mathrm{~cm} \\
120 \mathrm{~cm} \text { and } \\
80-99 \mathrm{~cm} \\
<80 \mathrm{~cm}\end{array}$ & $\begin{array}{l}\text { high } \\
\text { above very high } \\
\text { low } \\
\text { very low }\end{array}$ & $\begin{array}{l}712 \\
10 \\
1 \\
339 \\
99\end{array}$ & $\begin{array}{l}61.3 \\
0.9 \\
0.1 \\
29.2 \\
8.5\end{array}$ & 28.176 & $0.030 *$ \\
\hline
\end{tabular}

Note: *(P-value less than 0.5$) ; * *(\mathrm{P}$ - value less than $0.000 \mathrm{I})$, ***( $\mathrm{P}$ - value less than 0.0000$)$

Abbreviations: HTN (hypertention); *( $\mathrm{p}$-value less 0.5$)$; ${ }^{* *}(\mathrm{p}$-value less than $0.000 \mathrm{I}) ;{ }^{* * *}(\mathrm{p}$-value less than 0.0000$)$.

regularly eaten by respondents. Additionally, this study also found positive associations between participants who responded "Don't know" and "NO" to whether their family member is hypertensive or not.

\section{Discussion}

This study included a total sample of 1,161 students from SHS. There were more females than males as shown in
Table 1, and were all at the SHS level, which represents adolescent respondents. Due to resource challenges, multiple readings were conducted for only participants who recorded higher BP at first reading. This current study on SHS students reveals a high prevalence of hypertension on the future generation of Ghana, with almost $40 \%$ with preHTN and a little over 5\% with stages 1 and 2 HTN. This corresponds to the already existed literature of a $26.1 \%$ 


\section{Distribution of HTN by age}

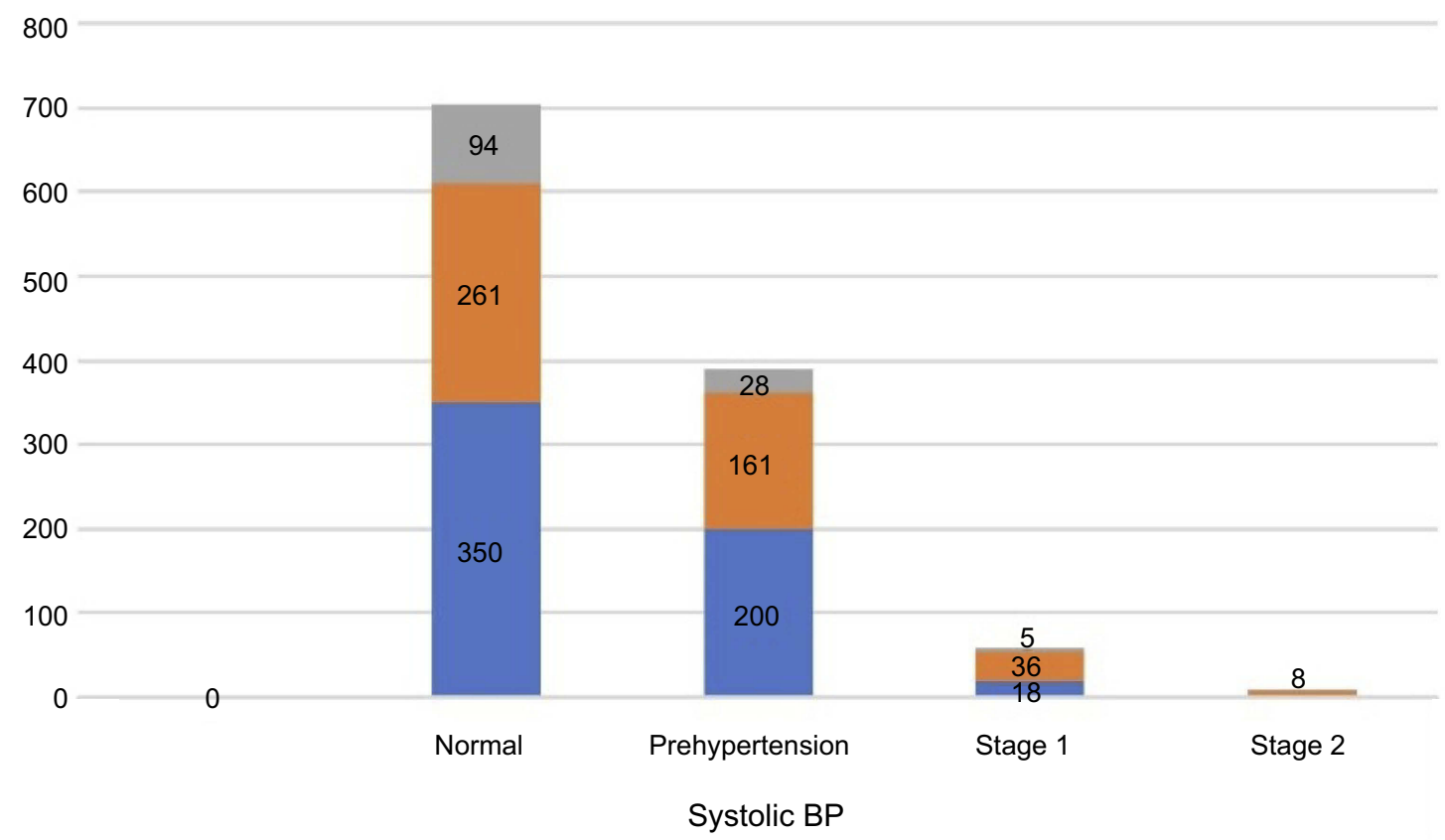

Age $15-17$ Age 18 and above Age less than 15

Figure I Distribution of HTN by age of respondents.

Abbreviations: HTN, Hypertension; BP, Blood pressure.

\section{Distribution of HTN by gender}

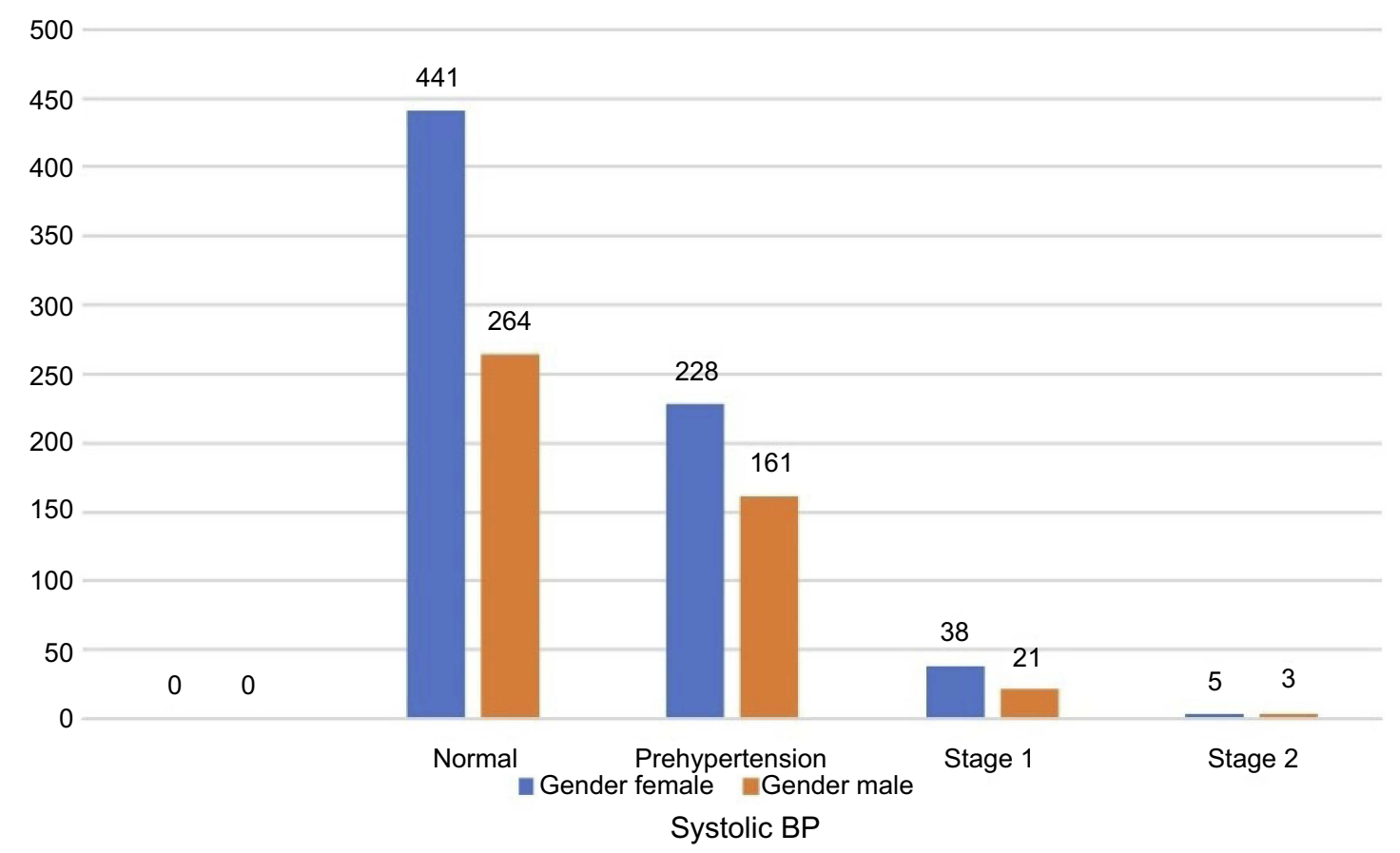

Figure 2 Distribution of HTN by gender of respondents. Abbreviations: HTN, hypertension; BP, Blood Pressure. 
Table 2 Knowledge on hypertension

\begin{tabular}{|l|l|l|}
\hline Do you have an idea of what hypertension is? & 733 & 63.1 \\
No & 428 & 36.9 \\
Yes & & \\
\hline Does anyone in your family have hypertension? & 607 & 52.3 \\
Don't know & 391 & 33.7 \\
No & 163 & 14.0 \\
Yes & & \\
\hline Have you been diagnosed of hypertension before? & 1126 & 97.0 \\
No & 35 & 3.0 \\
Yes & & \\
\hline What do you think are the causes of hypertension? & 409 & 40.9 \\
Don't know & 12 & 1.0 \\
Alcohol & 16 & 1.4 \\
Fat in the body & 18 & 1.6 \\
High cholesterol & 150 & 12.9 \\
High intake of salt & 6.9 \\
Irregular exercise & 4.0 \\
Stress & 14 \\
\hline Sugar & & 1.2 \\
\hline
\end{tabular}

prevalence of pre-HTN in students of the Kwame Nkrumah University of Science and Technology (KNUST). ${ }^{17}$ Although their study may differ a bit by the age range of their sample, it depicts a future speedy increase of the disease among indigenes of this country if measures are not put in place. It also serves as a guide to perhaps why the adult HTN prevalence ranges within $19-48 \%{ }^{7}$ and denotes focusing more interventional measures on primary disease prevention at an earlier age rather than on adults where tertiary preventive measures normally become the option especially within the African communities and in the SubSaharan African where Ghana is located. This study also found positive associations between the background characteristics and anthropometric measurements such as age, height, weight, BMI and hip circumferences of both male and female with HTN as elaborated in Table 1.

Additionally, age and gender (female) were also found to have positive associations on knowledge of HTN as well. Age and gender have been recognized as causal factors for HTN and CVDs in general and has been a

Table 3 Association between Hypertension and other variables

\begin{tabular}{|c|c|c|c|c|c|c|}
\hline Variable & Frequency & Percentage & AOR & \multicolumn{2}{|l|}{$95 \% \mathrm{Cl}$} & P-Value \\
\hline \multicolumn{7}{|c|}{ (a) Association between ages, gender on knowledge of hypertension } \\
\hline \multicolumn{7}{|l|}{ Age (years) } \\
\hline $15-17$ & 571 & 49.2 & 0.404 & 0.255 & 0.638 & $0.000 * * *$ \\
\hline$\geq 18$ & 462 & 39.8 & 0.424 & 0.266 & 0.675 & $0.000 * * *$ \\
\hline$<15$ & 128 & 11.0 & 1.0 & 1.0 & 1.0 & 1.0 \\
\hline \multicolumn{7}{|l|}{ Gender } \\
\hline Female & 710 & 61.2 & 1.351 & 1.056 & 1.729 & $0.017 * *$ \\
\hline Male & 451 & 38.8 & 1.0 & 1.0 & 1.0 & 1.0 \\
\hline \multicolumn{7}{|c|}{ (b) Association between risk factors and Knowledge of hypertension } \\
\hline Diagnosed with metabolic syndrome (NO) & 1,029 & 88.6 & 0.927 & 0.614 & 1.400 & 0.719 \\
\hline \multicolumn{7}{|l|}{ Physical exercise (weekly) } \\
\hline$\geq 3$ times & 98 & 8.4 & 1.074 & 0.664 & 1.737 & 0.772 \\
\hline Not at all & 391 & 33.7 & 1.423 & 1.048 & 1.932 & $0.024 * *$ \\
\hline One to 2 times & 224 & 19.3 & 1.075 & 0.755 & 1.530 & 0.690 \\
\hline \multicolumn{7}{|l|}{ Do you add extra salt to cooked food? } \\
\hline No & 460 & 39.6 & 1.449 & 1.106 & 1.897 & $0.007 * *$ \\
\hline Yes & 701 & 60.4 & 1.0 & 1.0 & 1.0 & 1.0 \\
\hline \multicolumn{7}{|l|}{ Type of foods often eaten } \\
\hline Fast food & 321 & 27.6 & 4.788 & 1.208 & 18.988 & $0.026 * *$ \\
\hline Homemade food & 829 & 71.4 & 4.300 & 1.099 & 16.824 & $0.036 * *$ \\
\hline \multicolumn{7}{|l|}{ Family history of hypertension } \\
\hline Don't know & 607 & 52.3 & 5.099 & 3.453 & 7.528 & $0.000 * * *$ \\
\hline No & 391 & 33.7 & 3.548 & 2.366 & 5.322 & $0.000 * * *$ \\
\hline
\end{tabular}

Note: ${ }^{*}(\mathrm{P}$ - value less than 0.5$) ;{ }^{* *}(\mathrm{P}$ - value less than $0.000 \mathrm{I}),{ }^{* * * *}(\mathrm{P}$ - value less than 0.0000$)$. 
central part of virtually all currently recognized risk algorithms for cardiac ailments, ${ }^{18,19}$ and this study conforms to those existing literature. This study gives a clear and concise background on the knowledge of people who could be classified as "the future of the nation" toward HTN and depicts a high gap on knowledge. Majority, $63.1 \%$, have "No idea" and $40.9 \%$ of participants "Don't know" what HTN is and the causes of HTN respectively. Studies have shown that gaps in knowledge in the form of health literacy are key hindrances to effectively avoid and treat HTN, as these permits individuals to progress on outcomes of their health. ${ }^{10,11}$ Having access to excellent information on health also improves knowledge on its management and control and this is on HTN as well. ${ }^{20}$ High knowledge on HTN at this stage in the lives of participants may go a long way to help decrease the future prevalence within Ghana and Africa as a whole since situations may not be very different in other parts of the continent.

This study, however, further found age, gender (female), not doing physical exercises at all, not adding extra salt, fast and homemade foods as risks factors with positive associations to knowledge on HTN among its respondents. There were no positive associations on HTN and BMI, HTN and male gender and hip circumference on Knowledge of HTN Interestingly, though dietary salt is related to $\mathrm{HTN},{ }^{21}$ this study rather demonstrated otherwise disputing association of salt and hypertension, suggesting a probable relation of salt and hypertension in older ages rather than in the adolescents. It also found a positive association between both fast and homemade foods regularly consumed by participants. Ghanaian youths have the habits of consuming more carbohydrates, proteins and fats, and this can alter blood pressure. ${ }^{22}$ Although BMI and hip circumferences have been found as predictors to HTN ${ }^{23}$ this current study did not find such an association though it is not disputing the facts of existing literature. Also, the study realized a positive relation between no physical activity and hypertension, which confirms existing literature of recommending physical reduction of HTN among risk population and hypertensive patients. ${ }^{24,25}$

\section{Conclusion}

The study has unveiled the prevalence of hypertension in its different stages. As well as knowledge, and risk factors of pre-HTN and HTN in an adolescent population that had not been targeted. This study indicates an educational intervention program on HTN, its prevalence and risks in the educational curriculum. Educating Domestic Bursars and Matrons who oversee feeding students in various schools in the Ghana education services on such topics is also warranted.

The major limitation of the study was first, the Blood Pressure measured was performed one's to confirm the diagnosis, whereas standard practice is to do it in at least three instances. Second, the sample location was mainly in Ashanti, a region in Ghana in public schools. This may not be a true representation of the country's population. Third, Field S2019 which we undertook had no probing questions but with yes or no type of questions.

\section{Availability of data}

All data analyzed for this article are included in the published paper. All other documents and data are available with the corresponding author and can be released on reasonable request.

\section{Acknowledgments}

The authors wish to recognize the Ashanti Regional Director of Education (Mrs. Mary Owusu Achiaw) and workers of the Ghana Education Services in the Ashanti region for their support. The authors also wish to thank nurses and doctors of Akomaa Memorial Hospital, Bekwai-Kortwia especially Mr. Stephen Kwarteng Frimpong and Mr. James Govina of Center for Scientific Institute of Research (CSIR) KNUST for their immense contribution to the script and collection of data.

\section{Author contributions}

All authors contributed to data analysis, drafting or revising the article, gave final approval of the version to be published, and agree to be accountable for all aspects of the work.

\section{Disclosure}

The authors report no conflicts of interest in this work.

\section{References}

1. Nahimana M-R, Nyandwi A, Muhimpundu AM, et al. A populationbased national estimate of the prevalence and risk factors associated with hypertension in Rwanda: implications for prevention and control. BMC Public Health. 2017;18:2. doi:10.1186/s12889-017-4536-9

2. Hien HA, Tam NM, Tam V, Derese A, Devroey D. Prevalence, awareness, treatment, and control of hypertension and its risk factors in (Central) vietnam. Int J Hypertens. 2018;2018:1-12. doi:10.1155/ $2018 / 6326984$

3. van de Vijver SJM, Oti SO, Agyemang C, Gomez GB, Kyobutungi C. Prevalence, awareness, treatment and control of hypertension among slum dwellers in Nairobi, Kenya. J Hypertens. 2013;31:1018-1024. doi:10.1097/HJH.0b013e32835e3a56 
4. Guwatudde D, Mutungi G, Wesonga R, et al. The epidemiology of hypertension in Uganda: findings from the national non-communicable diseases risk factor survey. PLoS One. 2015;10:e0138991. doi:10.1371/journal.pone.0138991

5. Yeboah EA. Dietary Factors Associated with Hypertension among Adults in Asesewa in the Upper Manya Krobo District. Available from: http://ugspace.ug.edu.gh/browse?type=author\&value=Yeboah \%2C+E.A. Accessed 15 July, 2019.

6. Agyemang, C., Attah-Adjepong, G, Ewusu-Dabo, E, et al. Stroke in Ashanti region of Ghana. Ghana Med J. 2012;46:12-17.

7. Agyei-Baffour P, Tetteh G, Quansah DY, Boateng D. Prevalence and knowledge of hypertension among people living in rural communities in Ghana: a mixed method study. Afr Health Sci. 2018;18:931-941. doi:10.4314/ahs.v18i4.12

8. Sanuade OA, Boatemaa S, Kushitor MK. Hypertension prevalence, awareness, treatment and control in Ghanaian population: evidence from the Ghana demographic and health survey. PLoS One. 2018;13: e0205985. doi:10.1371/journal.pone.0205985

9. Falkner B. Prehypertension in adolescents: how high is the risk for hypertension? J Pediatr. 2012;160:7-9. doi:10.1016/j.jpeds.2011.08.050

10. Jolles EP, Clark AM, Braam B. Getting the message across. J Hypertens. 2012;30:1500-1510. doi:10.1097/HJH.0b013e32835476e1

11. Poureslami I, Nimmon L, Rootman I, Fitzgerald MJ. Health literacy and chronic disease management: drawing from expert knowledge to set an agenda. Health Promot Int. 2016;32:daw003. doi:10.1093/ heapro/daw003

12. Kilic M, Uzunçakmak T, Ede H. The effect of knowledge about hypertension on the control of high blood pressure. Int $J$ Cardiovasc Acad. 2016;2:27-32. doi:10.1016/j.ijcac.2016.01.003

13. [No authors listed]. Report of the second task force on blood pressure control in children-1987. Task force on blood pressure control in children. National Heart, Lung, and Blood Institute, Bethesda, Maryland. Pediatrics. 1987;79:1-25.

14. Anyaegbu EI, Dharnidharka VR. Hypertension in the teenager. Pediatr Clin North Am. 2014;61:131-151. doi:10.1016/j.pcl.2013.09.011
15. Dzudie A, Rayner B, Ojji D, et al. Roadmap to achieve $25 \%$ hypertension control in Africa by 2025. Cardiovasc J Afr. 2017;28:262272. doi:10.5830/CVJA-2017-040

16. Cuddy MLS. Treatment of hypertension: guidelines from JNC 7 (the seventh report of the joint national committee on prevention, detection, evaluation, and treatment of high blood pressure 1). J Pract Nurs. 2005;55:17-21; quiz 22-3.

17. Gyamfi D, Obirikorang C, Acheampong E, et al. Prevalence of prehypertension and hypertension and its related risk factors among undergraduate students in a Tertiary institution, Ghana. Alexandria J Med. 2018;54:475-480. doi:10.1016/j.ajme.2018.02.002

18. Agyemang C. Rural and urban differences in blood pressure and hypertension in Ghana, West Africa. Public Health. 2006;120:525533. doi:10.1016/j.puhe.2006.02.002

19. Agyemang C, Redekop WK, Owusu-Dabo E, Bruijnzeels MA. Blood pressure patterns in rural, semi-urban and urban children in the Ashanti region of Ghana, West Africa. BMC Public Health. 2005;5:114. doi:10.1186/1471-2458-5-49

20. Bigi, M. A. B., Zibaeenezhad, MJ, Aghasadeghi K, Jokar A, Shekarforoush S, Khazraei $\mathrm{H}$. The effect of educational programs on hypertension management. Int Cardiovasc Res J. 2017;8;1.

21. Frisoli TM, Schmieder RE, Grodzicki T, Messerli FH. Salt and hypertension: is salt dietary reduction worth the effort? $\mathrm{Am} \mathrm{J} \mathrm{Med}$. 2012;125:433-439. doi:10.1016/j.amjmed.2011.10.023

22. Hodges RE, Rebello T. Carbohydrates and blood pressure. Ann Intern Med. 1983;98:838-841. doi:10.7326/0003-4819-98-5-838

23. Roka R, Michimi A, Macy G. High blood press. Cardiovasc Prev. 2015.23(3);265.

24. Diaz KM, Shimbo D. Physical activity and the prevention of hypertension. Curr Hypertens Rep. 2013;15:659-668. doi:10.1007/s11906-013-0386-8

25. Börjesson M, Onerup A, Lundqvist S, Dahlöf B. Physical activity and exercise lower blood pressure in individuals with hypertension: narrative review of 27 RCTs. Br J Sports Med. 2016;50:356-361. doi:10.1136/bjsports-2016-096014

\section{Publish your work in this journal}

Diabetes, Metabolic Syndrome and Obesity: Targets and Therapy is an international, peer-reviewed open-access journal committed to the rapid publication of the latest laboratory and clinical findings in the fields of diabetes, metabolic syndrome and obesity research. Original research, review, case reports, hypothesis formation, expert opinion and commentaries are all considered for publication. The manuscript management system is completely online and includes a very quick and fair peer-review system, which is all easy to use. Visit http://www.dovepress.com/testimonials.php to read real quotes from published authors. 